\title{
Preserving Intellectual Freedom in Clinical Medicine
}

\author{
Giovanni A. Fava \\ Department of Psychology, University of Bologna, Bologna, Italy; Department of Psychiatry, \\ State University of New York at Buffalo, Buffalo, N.Y., USA
}

An eminent clinician of the past century, John A. Ryle, summarized the social responsibilities of the physician as follows: 'The life and work of the physician proceed under the direction of three main influences: the scientific, the humane, and the ethical. Whereas other men of science have, until now, found it possible to pursue their intellectual tasks without reference to human need and without regard for ethical considerations other than those immediately connected with the pursuit of the truth and respect for colleagues, the medical man has carried a far heavier and more complex burden of responsibility. He has had and has now in ever-increasing measure - and in the addition to the consideration which he owes to himself and his dependants - a special duty to his patients, to the community, to his colleagues, and to his science or calling' [1, p. 101].

These are values which Robert G. Petersdorf echoed 4 decades later, in 1989: 'We can no longer tolerate the dishonesty, cheating, fraud, and conflict of interest that have invaded science and medicine. By choosing these professions we have assumed a trust that is predicated upon integrity. We must not deviate from it' [2, p. 123].

Halstead R. Holman, in a paper published in Hospital Practice in 1976 [3], which anticipated some of the developments in health care over the following 4 decades, observed that 'the medical establishment is not primarily engaged in the disinterested pursuit of knowledge into medical practice; rather in significant part it is engaged in special interest advocacy, pursuing and preserving social power. The concept of excellence is a component of the ideological justification of that role' [3, p. 11]. Holman identified a decline in intellectual freedom as a major source of the 'excellence deception', which perpetuates prevailing practices, deflects criticism and insulates the profession from alternative views and social relations that would illuminate and improve health care. There are indeed increasing threats to the preservation of intellectual freedom in clinical medicine.

\section{The Many Faces of Censorship}

There have been growing concerns about the independence of academic medicine [4-7]. Corporate interests may result in self-selected academic oligarchies (special interest groups) that influence clinical and scientific information [5]. Members of special interest groups are not simply the easily recognizable prodigal experts who move from one meeting to another to illustrate the wonderful properties of the drugs to be launched, who have their slides prepared and checked by the companies, who sign ghostwritten papers and are promptly substituted if they do not have impact on prescriptions [8]. They are also the gatekeepers of corporate interest in scientific informa-

\section{KARGER}

Fax +4161306 1234 E-Mail karger@karger.ch www.karger.com
(C) 2008 S. Karger AG, Basel

0033-3190/09/0781-0001\$26.00/0

Accessible online at:

www.karger.com/pps
G.A. Fava, MD

Department of Psychology, University of Bologna

Viale Berti Pichat, 5

IT-40127 Bologna (Italy)

Tel. +39 051209 1339, Fax +39051 243 086, E-Mail giovanniandrea.fava@unibo.it 
tion. They act as editors, reviewers and consultants to medical journals, scientific meetings and nonprofit research organizations, with the task of systematically preventing dissemination of data that may be in conflict with the special interest they represent [5].

By carefully selecting the literature in a biased direction and offering a manipulated interpretation of clinical trials (including those supported by public sources) they become 'the role models whose views are to be taken seriously' [9]. The drug industry may thus take control of scientific societies, clinical practice guidelines and reporting investigations in meetings and journals. Independent investigators, who feel the moral obligation to tell the truth, may object to the manipulation of evidence operated by these special interest groups, who retaliate: excluding them from symposia, removing them from academic appointments and preventing access to sources of research funding [10]. Isolation is the ultimate outcome. For a pharmaceutical company delaying or minimizing knowledge of a side effect of a medication has cash value. Similarly, not publishing negative studies may shift the balance of subsequent meta-analyses. A recent paper [11] provides a good illustration as to how selected publication of antidepressant trials affects their apparent efficacy. Thirty-seven of the 74 FDA-registered studies that were associated with positive outcomes were published and 1 was not, whereas only 3 of the 36 negative studies were published [11]. Physicians who are not familiar with the scientific method may rely on meta-analyses for choosing their therapeutic tools [12]. Censorship may thus be the result of direct prevention of publication and dissemination of findings by the pharmaceutical company itself (displaying its power as an advertiser in medical journals, a supporter of meetings and the owner of the data) or by special interest groups (the trusted opinion leaders).

Yet, there are more subtle forms of censorship. One has to do with setting a financial threshold for publishing research findings. In recent years, there has been a progressive demand for the free availability of resources on the internet and for centralizing medical information. Public access to medical journals means that the authors will have to pay at least part of the expenses. Publications loaded with conflicts of interest would not really have any problem; however, this will be a major difficulty for young and unsupported investigators. These investigators, because of their inquisitive nature that may lead to new discoveries, are the lifeblood of science [10]. The issue is thus not open access to self-selected information, but the discrimination of independent sources within information overload [13].
Another subtle form of censorship is by counteracting undesirable published information with massive doses of propaganda. Noam Chomsky has been instrumental in disclosing the link between propaganda and media control [14]. Filtering information (selective perception), engineering opinions, using the public relations industry and marginalizing dissident cultures are the well-known modalities of action. The presentation of the literature on long-term treatment with antidepressant drugs exemplifies this strategy [15].

Yet, it is deliberate self-censorship that may yield the most dangerous effects. As suggested by a recent survey of journalists [16], it is common and eliminates the need for editorial cuts and modifications. The typical example is the intervention of an established investigator in a drug-sponsored symposium. He or she refrains from making promotional statements, leaving the dirty job to someone else in the symposium. However, he or she does not comment on unsubstantiated and commercial statements from other speakers in the panel.

Obviously, financial interests are not the only source of censorship in clinical medicine, and may be substituted or supplemented by cultural, political and ideological issues.

If medical knowledge is the cumulative experience of human history, 'a legacy from those who have gone before to those who live today' and 'a social possession' [3, p. 21], then the suppression of memory (i.e. reliance on the most recent papers) and ignorance of the historical intellectual debate may be other more subtle forms of censorship. Noam Chomsky, in an essay on the intellectual climate during the Cold War [17], reminds us of how the neglect of the history of the disciplines was instrumental to preventing a critical attitude toward the establishment. If we do not know where we came from, we have a very poor idea of where we are going to.

\section{Preserving Intellectual Freedom}

Viewing censorship simply in terms of power from special interest groups would be too simplistic. The submission process of scientific publications (with methodological requirements, peer reviews, journals' priorities and space) may also be perceived as a form of censorship. Would uncensored exchange of scientific results solve the problem? Not quite [13]. The challenge is to preserve pluralism, critical thinking and intellectual freedom in a setting more and more characterized by conformism, political appropriateness and the cult of mediocrity [18]. 
One way to address the problem has recently been suggested $[5,19]$, and has to do with the value that is represented by investigators who opted for not having any substantial conflicts of interest (i.e. being an employee of a private firm; being a regular consultant or in the board of directors of a firm; being a stockholder of a firm related to the field of research; owning a patent directly related to the published work) [5]. These criteria, which are based on work by Krimsky et al. [20], involve the concept of continuity of a relationship with a private firm. Occasional consultancies, grants for performing investigations, or receiving honoraria or refunds on specific occasions would not be a source of substantial conflict of interest [5]. We are often told that virtually all clinical investigators should have some ties with the industry, even though this is not true (and the characteristics of these relationships may vary a great deal) [21]. Researchers without substantial conflicts of interest, however, need support, which includes priority for obtaining grants from public agencies supported by taxpayers' money and priorities, for key positions in scientific societies and journal editorships. Clinical practice guidelines should be reserved to these investigators. Otherwise, the scientific community would soon drain itself of a reservoir of truly independent experts who can be called to advise government policy makers on the safety and efficacy of treatments, on the hazards of chemicals and on the safety of technology [20]. Taxpayers and members of professional societies deserve scientific leadership by those researchers who opt to be devoid of substantial conflicts of interest, and may counteract the feudal lords of medicine [10] and the artificial boundaries that the game of power has built in the medical system. The recent questioning of the American Psychiatric Association's financial management [22] underscores the need for major changes in leadership and handling the issue of conflict of interest.

\section{The Journal's Mission}

In line with the task that was set in the early nineties [23], this journal has tried to foster innovative and unconventional thinking at the interface between medical and behavioral sciences. Chomsky subdivides intellectuals into 2 categories: 'the "technocratic and policy-oriented intellectuals" - responsible, sober, constructive - and the "value-oriented intellectuals", a sinister grouping who pose a threat to democracy as they devote themselves to the derogation of leadership, the challenging of authority, and the unmasking of established institutions' [24, p. 214].
This journal seems to attract more and more 'valueoriented' scientists. As much as it can be judged by a crude and rough estimate such as the impact factor, its content does not pass unnoticed. The journal's 2007 Journal Citation Reports impact factor is 5.02, which places the journal as number 9 in the psychiatry ranking and number 4 (but actually the top journal among those that publish original investigations) in the psychology ranking. We have tried not to forget what the histories of our disciplines teach, with tributes to outstanding clinical scientists [25-28].

We will also try to be open to different and dissenting views, in the spirit Thomas Jefferson so aptly summarized: 'If [the] book be false in its facts, disprove them; if false in its reasoning, refute it. But, for God's sake, let us freely hear both sides, if we choose.'

\section{Appendix}

The following experts have supplemented the editorial board by reviewing the manuscripts submitted to Psychotherapy and Psychosomatics during 2008, and are gratefully acknowledged. We would like to thank also Carlotta Belaise, who has taken care of press releases. Both external referees and editorial board members have disclosed potential conflicts of interest. The Editor-inChief has no conflict of interest to declare for 2008.

\begin{tabular}{lll}
\hline Name & City & Country \\
\hline G. Abbate-Daga & Turin & Italy \\
J. Alder & Basel & Switzerland \\
A. Andreoli & Geneva & Switzerland \\
B.J. Arnetz & Detroit, Mich. & United States \\
R.J. Baldessarini & Boston, Mass. & United States \\
M. Battaglia & Milan & Italy \\
B. Baune & Townsville & Australia \\
C. Belaise & Bologna & Italy \\
F. Benazzi & Forli & Italy \\
M. Beresnevaite & Kaunas & Lithuania \\
T.K. Bouman & Groningen & The Netherlands \\
A. Bravi & Bologna & Italy \\
S. Büchi & Zurich & Switzerland \\
G. Cizza & Bethesda, Md. & United States \\
M. Chiesa & Richmond & United Kingdom \\
D. Cohen & Paris & France \\
F. Cosci & Firenze & Italy \\
J.A. Cottraux & Lyon & France \\
K. Davidson & Glasgow & United Kingdom \\
J. de Figuereido & Cheshire, Conn. & United States \\
I. Franken & Rotterdam & The Netherlands \\
J. De Fruyt & Brugge & Belgium \\
S. Einsendrath & San Francisco, Calif. & United States \\
R. El Mallakh & Louisville, Ky. & United States \\
S. Fabbri & Charlottesville, Va. & United States \\
\hline & &
\end{tabular}




\begin{tabular}{|c|c|c|c|c|c|}
\hline Name & City & Country & Name & City & Country \\
\hline F. Facchinetti & Modena & Italy & B. Metternich & Freiburg & Germany \\
\hline F. Fallo & Padova & Italy & N. Micali & London & United Kingdom \\
\hline C. Faravelli & Florence & Italy & R. Mojtabai & New York, N.Y. & United States \\
\hline E. Ferguson & Nottingham & United Kingdom & A. Moreira-Almeda & Durham, N.C. & United States \\
\hline A. Finset & Oslo & Norway & P.L. Morosini & Rome & Italy \\
\hline B. Gaudiano & Providence, R.I. & United States & A.A. Nierenberg & Boston, Mass. & United States \\
\hline A.T. Gloster & Dresden & Germany & H. Ochitill & San Francisco, Calif. & United States \\
\hline H.J. Grabe & Stralsund & Germany & E. Offidani & Bologna & Italy \\
\hline L. Grassi & Ferrara & Italy & F. Ottolini & Bologna & Italy \\
\hline N. Greenberg & London & United Kingdom & C. Peretti & Paris & France \\
\hline P. Gremigni & Bologna & Italy & T. Petersen & Boston, Mass. & United States \\
\hline J. Guidi & Bologna & Italy & A. Picardi & Rome & Italy \\
\hline M. Haerter & Freiburg & Germany & P. Porcelli & Bari & Italy \\
\hline D. Healy & Bangor Gwynedd & United Kingdom & M. Rigatelli & Modena & Italy \\
\hline M. Hengeveld & Rotterdam & The Netherlands & V. Romei & Ginevra & Switzerland \\
\hline S. Hetrick & Melbourne & Australia & J.K. Salminen & Turku & Finland \\
\hline P. Hoglend & Oslo & Norway & F. Semprini & Bologna & Italy \\
\hline E. Jannini & L'Aquila & Italy & S. Shiri & Tel Aviv & Israel \\
\hline L. Jaycox & Pittsburgh, Pa. & United States & B. Singer & Princeton, N.J. & United States \\
\hline E. Joosten & Nijmegen & The Netherlands & L. Sirri & Bologna & Italy \\
\hline N. Kawamura & Tokyo & Japan & N. Sonino & Padova & Italy \\
\hline B. Kraemer & Zurich & Switzerland & D. Spiegel & Stanford, Calif. & United States \\
\hline S. Krimsky & Boston, Mass. & United States & L. Staccini & Bologna & Italy \\
\hline C. Kuehner & Mannheim & Germany & J. Stone & Edinburgh & United Kingdom \\
\hline C. Lai & Rome & Italy & L. Tarsitani & Roma & Italy \\
\hline J. Leckman & New Haven, Conn. & United States & E. Tossani & Bologna & Italy \\
\hline P. Leombruni & Turin & Italy & A. van Balkom & Amsterdam & The Netherlands \\
\hline S. Levenstein & Rome & Italy & S. Vanheule & Ghent & Belgium \\
\hline M.M. Linehan & Seattle, Wash. & United States & P.D. Wadhwa & Irvine, Calif. & United States \\
\hline A. Lobo & Zaragoza & Spain & N. Watanabe & Nagoya & Japan \\
\hline S. Loeber & Mannheim & Germany & J. Wiltink & Mainz & Germany \\
\hline T. Lundin & Uppsala & Sweden & D. Visani & Bologna & Italy \\
\hline G. Maina & Torino & Italy & C. Zimmermann & Verona & Italy \\
\hline L. Mangelli & Bologna & Italy & & & \\
\hline
\end{tabular}

\section{References}

1 Ryle JA: Changing Disciplines: Lectures on the History, Method and Motives of Social Pathology. London, Oxford University Press, 1948.

$\checkmark 2$ Petersdorf RG: A matter of integrity. Acad Med 1989;64:119-123.

$\checkmark 3$ Holman HR: The 'excellence' deception in medicine. Hosp Pract 1976;11:11-21.

$\checkmark 4$ Lexchin J, Light DW: Commercial influence and the content of medical journals. BMJ 2006;332:1444-1447.

5 Fava GA: Financial conflicts of interest in psychiatry. World Psychiatry 2007;6:19-24.

$\checkmark 6$ Healy D: Irrational healers. Psychother Psychosom 2008;77:198-200.
7 Nierenberg AA, Smoller JW, Eidelman P, Wu YP, Tilley CA: Critical thinking about adverse drug effects: lessons from the psychology of risk and medical decision-making for clinical psychopharmacology. Psychother Psychosom 2008;77:201-208.

8 Moynihan R: Key opinion leaders: independent experts or drug representatives in disguise? BMJ 2008;336:1402-1403.

$\checkmark 9$ Iheanacho I: Paying for the view. BMJ 2008; 336:160.

10 Borgstein J, Watine J: Feudal lords of science and medicine. West J Med 2001;175:139-140.

11 Turner EH, Matthews AM, Linardatos E, Tell RA, Rosenthal R: Selective publication of antidepressant trials and its influence on apparent efficacy. N Engl J Med 2008;358: 252-260.
12 Feinstein AR: Meta-analysis: statistical alchemy for the 21st century. J Clin Epidemiol 1995;48:71-79.

13 Fava GA, Guidi J: Information overload, the patient and the clinician. Psychother Psychosom 2007;76:1-3.

14 Chomsky N: Media Control: The Spectacular Achievements of Propaganda. New York, Seven Stories, 1997.

15 Fava GA: Long-term treatment with antidepressant drugs: the spectacular achievements of propaganda. Psychother Psychosom 2002;71:127-132.

$>16$ Lee FLF, Chan JM: Professionalism, political orientation, and perceived self-censorship. Issue Studies 2008;44:205-238. 
17 Chomsky N: The cold war and the university; in Chomsky N, Katznelson I, Lewontin RC, Montgomery D, Nader L, Ohmann R, Siever R, Wallerstein I, Zinn H: The Cold War \& the University. New York, New Press, 1997, pp 171-194.

18 Fava GA: The cult of mediocrity. Psychother Psychosom 2005;74:1-2.

19 Fava GA: Should the drug industry use key opinion leaders? No. BMJ 2008;336:1045.

$>20$ Krimsky S, Rothenberg LS, Stott P, Kyle G: Scientific journals and their authors' financial interests: a pilot study. Psychother Psychosom 1998;67:194-201.
-21 Campbell EG, Gruen RL, Mountford J, Miller LG, Cleary PD, Blumenthal D: A national survey of physician-industry relationships. N Engl J Med 2007;356:1742-1750.

22 Carey B, Harris G: Psychiatric group faces scrutiny over drug industry ties. New York Times, July 12, 2008.

23 Fava GA: The journal's task. Psychother Psychosom 1992;57:1-2.

24 Chomsky N: Interventions. San Francisco, City Lights Books, 2007.

25 Nierenberg AA, Sonino N: From clinical observations to clinimetrics: a tribute to Alvan R. Feinstein, MD. Psychother Psychosom 2004;73:131-133.
26 Bech P: The full story of lithium: a tribute to Mogens Schou (1918-2005). Psychother Psychosom 2006;75:265-269.

27 De Figuereido JM: Demoralization and psychotherapy: a tribute to Jerome D. Frank, MD, PhD (1909-2005). Psychother Psychosom 2007;76:129-133.

28 Fava GA, Rafanelli C, Tossani E, Grandi S: Agoraphobia is a disease: a tribute to Sir Martin Roth. Psychother Psychosom 2008; 77:133-138. 